\title{
Comparison of calculated and experimental isotope edited FTIR difference spectra for purple bacterial photosynthetic reaction centers with different quinones incorporated into the $\mathrm{Q}_{\mathrm{A}}$ binding site
}

\author{
Nan Zhao, Hari P. Lamichhane and Gary Hastings* \\ Department of Physics and Astronomy, Georgia State University, Atlanta, GA, USA
}

\section{Edited by:}

Harvey J. M. Hou, Alabama State

University, USA

\section{Reviewed by:}

Suleyman I. Allakhverdiev, Russian Academy of Sciences, Russia

Art Van Der Est, Brock University, Canada

\section{${ }^{*}$ Correspondence:}

Gary Hastings, Department of

Physics and Astronomy, Georgia

State University, 26 Park Place,

Suite 605., Atlanta, GA 30303, USA

e-mail: ghastings@gsu.edu
Previously we have shown that ONIOM type (QM/MM) calculations can be used to simulate isotope edited FTIR difference spectra for neutral ubiquinone in the $\mathrm{Q}_{A}$ binding site in Rhodobacter sphaeroides photosynthetic reaction centers. Here we considerably extend upon this previous work by calculating isotope edited FTIR difference spectra for reaction centers with a variety of unlabeled and ${ }^{18} \mathrm{O}$ labeled foreign quinones incorporated into the $\mathrm{Q}_{A}$ binding site. Isotope edited spectra were calculated for reaction centers with 2,3-dimethoxy-5,6-dimethyl-1,4-benzoquinone $\left(\mathrm{MQ}_{0}\right)$, 2,3,5,6-tetramethyl-1, 4-benzoquinone (duroquinone, DQ), and 2,3-dimethyl-I,4-naphthoquinone (DMNQ) incorporated, and compared to corresponding experimental spectra. The calculated and experimental spectra agree well, further demonstrating the utility and applicability of our ONIOM approach for calculating the vibrational properties of pigments in protein binding sites. The normal modes that contribute to the bands in the calculated spectra, their composition, frequency, and intensity, and how these quantities are modified upon ${ }^{18} \mathrm{O}$ labeling, are presented. This computed information leads to a new and more detailed understanding/interpretation of the experimental FTIR difference spectra. Hydrogen bonding to the carbonyl groups of the incorporated quinones is shown to be relatively weak. It is also shown that there is some asymmetry in hydrogen bonding, accounting for $10-13 \mathrm{~cm}^{-1}$ separation in the frequencies of the carbonyl vibrational modes of the incorporated quinones. The extent of asymmetry in $\mathrm{H}$-bonding could only be established by considering the spectra for various types of quinones incorporated into the $\mathrm{Q}_{A}$ binding site. The quinones listed above are "tail-less." Spectra were also calculated for reaction centers with corresponding "tail" containing quinones incorporated, and it is found that replacement of the quinone methyl group by a phytyl or prenyl chain does not alter ONIOM calculated spectra.

\section{Keywords: ONIOM, FTIR, QA, quinone, reaction center, density functional theory (DFT) calculations}

\section{INTRODUCTION}

Quinones play an important role in biological proton and electron transfer processes that occur in both respiration and photosynthesis (Trumpower, 1982). In type II photosynthetic reaction centers two quinone molecules act as terminal electron acceptors $(\mathrm{Ke}, 2001 \mathrm{a}, \mathrm{b})$. The two quinones are often termed $\mathrm{Q}_{\mathrm{A}}$ and $\mathrm{Q}_{\mathrm{B}}$. In this manuscript we will refer to the quinone binding site as $\mathrm{Q}_{A}$ and $\mathrm{Q}_{B}$, however. The quinones that occupy the $\mathrm{Q}_{A}$ and $\mathrm{Q}_{B}$ binding sites have very different functions. The $\mathrm{Q}_{A}$ quinone

Abbreviations: Ala, alanine; DS, difference spectra/spectrum spectroscopy or spectroscopic; $\mathrm{C}=\mathrm{O}$, carbonyl; $\mathrm{DQ}$, duroquinone or 2,3,5,6-tetramethyl-1,4benzoquinone; DFT, density functional theory; DMNQ, dimethyl naphthoquinone; ET, electron transfer; FTIR, Fourier Transform Infra-red; H-bond, hydrogen bond; His, histidine; $\mathrm{MQ}_{0}, 2,3$-dimethoxy-5,6-dimethyl-1,4-benzoquinone; $\mathrm{MM}$, molecular mechanics; NQ, naphthoquinone; PQ, plastoquinone; PBRC, purple bacterial reaction center; PED, potential energy distribution; Rb., Rhodobacter; $\mathrm{QM}$, quantum mechanics; $\mathrm{UQ}_{n}$, ubiquinone-n; $\mathrm{VK}$, vitamin $\mathrm{K}_{1}$ (phylloquinone). is an intermediary cofactor involved in transferring electrons from (bacterio) pheophytin to $\mathrm{Q}_{B}$, while the $\mathrm{Q}_{B}$ quinone couples proton and electron transfer processes (Ke, 2001b,c,d).

In this manuscript we focus on the $\mathrm{Q}_{\mathrm{A}}$ binding site. The quinone occupying the $\mathrm{Q}_{\mathrm{A}}$ binding site is species dependent. In Rhodobacter ( $R b$.) sphaeroides purple bacterial reaction centers (PBRCs) a ubiquinone (UQ) molecule occupies the $\mathrm{Q}_{\mathrm{A}}$ binding site. In PBRCs from Blastochloris viridis (Shopes and Wraight, 1985) and Chloroflexus aurantiacus (Hale et al., 1983) a menaquinone occupies the $\mathrm{Q}_{\mathrm{A}}$ binding site. In photosystem II reaction centers from oxygen evolving organisms, a plastoquinone (PQ) molecule occupies the $\mathrm{Q}_{\mathrm{A}}$ binding site. In photosystem I the secondary electron acceptor, termed $A_{1}$, is a vitamin $\mathrm{K}_{1}(\mathrm{VK})$ molecule (also called phylloquinone). Menaquinone and VK are both naphthoquinone (NQ) moieties that differ only in the degree of saturation of the tail at $\mathrm{C}_{6}$. 
Figure 1 shows the structure, numbering and abbreviations we will use for the various quinones discussed in this manuscript. $\mathrm{MQ}_{0}$ and DMNQ are UQ and VK analogues, respectively, in which the hydrocarbon tail has been replaced with a methyl group. DQ is a PQ analogue in which the hydrocarbon chain at $\mathrm{C}_{6}$ is replaced with a methyl group.

It has been suggested, at least for the UQ that occupies the $\mathrm{Q}_{\mathrm{A}}$ site in PBRCs, that the role of the hydrocarbon chain at $\mathrm{C}_{6}$ is to anchor and orient the quinone head-group in a specific way (Warncke et al., 1994). Data is available that may argue against this proposal, however, (McComb et al., 1990; Srinivasan and Golbeck, 2009; Wraight and Gunner, 2009).

Comparison of the properties of PBRCs with $\mathrm{MQ}_{0}$ and $\mathrm{UQ}_{n}$, or $\mathrm{VK}$ and $\mathrm{DMNQ}$, incorporated into the $\mathrm{Q}_{\mathrm{A}}$ binding site will allow one to assess how or if the hydrocarbon chain at $\mathrm{C}_{6}$ modifies the quinones functional properties. Similarly, comparison of the properties of PBRCs with $\mathrm{MQ}_{0}$ and $\mathrm{DQ}$ incorporated into the $\mathrm{Q}_{\mathrm{A}}$ binding site will allow one to assess how or if the methoxy groups at $\mathrm{C}_{2}$ and $\mathrm{C}_{3}$ modifies the quinones functional properties. Calculated spectra for $R b$. sphaeroides PBRCs with VK in the $\mathrm{Q}_{\mathrm{A}}$ binding site can be compared to experimental spectra. These calculated spectra may also serve as a useful model for $B$. viridis $\mathrm{PBRCs}$ that naturally have $\mathrm{VK}$ incorporated into the $\mathrm{Q}_{\mathrm{A}}$ binding site.

Fourier transform infrared (FTIR) difference spectroscopy (DS) is a sensitive molecular-level probe of pigment-protein interactions, and it is widely used to study both the neutral and reduced states of quinones in PBRCs (Breton and Nabedryk, 1996) and in photosystem II (Noguchi and Berthomieu, 2005). In this manuscript we focus on $Q_{A}^{-} / Q_{A}$ FTIR DS. Many molecular species contribute to $\mathrm{Q}_{\mathrm{A}}^{-} / \mathrm{Q}_{\mathrm{A}}$ FTIR DS, and in the past it has been difficult to identify which bands are associated specifically with UQ in the $Q_{A}$ site. However, fully functional quinones can be incorporated into $\mathrm{Q}_{\mathrm{A}}$ depleted PBRCs, and by collecting $\mathrm{Q}_{\mathrm{A}}^{-} / \mathrm{Q}_{\mathrm{A}}$

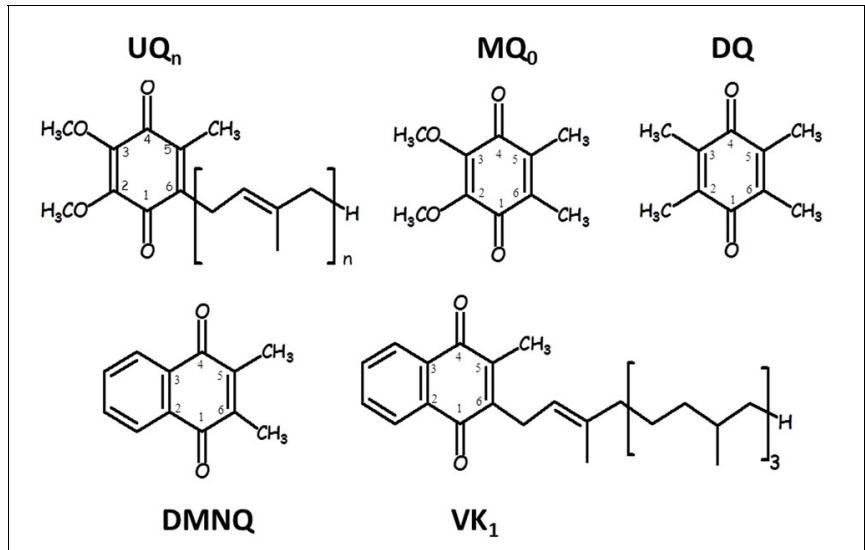

FIGURE 1 | Structure and numbering of ubiquinone (2,3-dimethoxy, 5-methyl,6-prenyl benzoquinone) ( $\left(\mathrm{O}_{n}\right)$, 2,3-dimethoxy, 5,6-methyl benzoquinone $\left(\mathrm{MO}_{0}\right), 2,3,5,6-\mathrm{methyl}$ benzoquinone (duroquinone, DO), 2,3-dimethyl, 1,4-naphthoquinone (DMNO) and 2-methyl, 3-phytyl 1,4-naphthoquinone (VK). The numbering scheme employed here for the naphthoquinone structures is nonstandard, and was chosen to facilitate comparison between naphthoquinone and ubiquinone structures.
FTIR DS using PBRCs with unlabeled and isotopically labeled quinones incorporated, so called isotope edited FTIR difference spectra can be constructed, and from these spectra it has proven possible to separate contributions of the quinones from those of the protein in $\mathrm{Q}_{\mathrm{A}}^{-} / \mathrm{Q}_{\mathrm{A}}$ FTIR DS (Breton and Nabedryk, 1996). Previously, a variety of unlabeled and ${ }^{18} \mathrm{O}$ labeled quinones have been incorporated into the $\mathrm{Q}_{\mathrm{A}}$ binding site in PBRC's, and ${ }^{18} \mathrm{O}$ isotope edited FTIR DS have been obtained (Breton et al., 1994a). The goal in this manuscript is the simulation of these experimental ${ }^{18} \mathrm{O}$ isotope edited FTIR DS associated with the neutral state of the quinone in the $\mathrm{Q}_{\mathrm{A}}$ binding site. Calculated IR spectra associated with the quinone anion state are considerably more complicated (Lamichhane and Hastings, 2013) and are currently being undertaken.

Although experimental $Q_{A}^{-} / Q_{A}$ FTIR DS have been obtained using PBRCs with various unlabeled and isotope labeled quinones incorporated, virtually no computational work aimed at modeling the experimental FTIR DS have been undertaken. Calculations aimed at modeling the vibrational properties of quinones in the $\mathrm{Q}_{\mathrm{A}}$ binding site must account for the protein environment. Quantum mechanical (QM) calculations of such a large molecular system (pigment plus protein environment) are unfeasible. To circumnavigate this problem methods have been developed that allow one to separate the molecular system into distinct layers that can be treated at different levels of theory. In one layer the chemical properties of the principle species of interest (the pigment) can be calculated using "high-level" QM methods. The surrounding protein environment is included in the calculation but it is treated using computationally less expensive molecular mechanics (MM) methods.

Recently, we have undertaken QM:MM calculations for UQ in the $\mathrm{Q}_{\mathrm{A}}$ binding site using the ONIOM method (Vreven et al., 2006). ONIOM is an acronym for: our Own N-layered Integrated molecular Orbital + Molecular mechanics package. In these calculations we showed that we could simulate experimental isotope edited FTIR difference spectra obtained using PBRCs with neutral $\mathrm{UQ}$ in the $\mathrm{Q}_{\mathrm{A}}$ binding site. Here we extend upon these previous studies by attempting to simulate experimental isotope edited FTIR difference spectra obtained using PBRCs with symmetric tail-less and corresponding tail containing quinones incorporated into the $\mathrm{Q}_{\mathrm{A}}$ binding site. We show that the calculated spectra agree well with the experimental spectra, further supporting the notion that the ONIOM method is a useful approach for understanding complex FTIR difference spectra associated with pigments in protein binding sites. We are also able to assess to what extent the quinone hydrocarbon chain may influence the calculated spectra.

\section{MATERIALS AND METHODS}

\section{STRUCTURAL MODEL USED IN CALCULATIONS}

The molecular model used in ONIOM calculations was generated from the crystal structure of $R b$. sphaeroides PBRCs at $2.2 \AA$ resolution (Stowell et al., 1997) (PDB file 1AIJ). From the PDB file all atoms within $10 \AA$ of either carbonyl oxygen atom of UQ were selected. This subset of atoms formed the basis of the $\mathrm{Q}_{\mathrm{A}}$ binding site structural model. Hydrogen atoms (not included in the PDB file) were added to the model using the software Gaussview4, resulting in a final structural model consisting of 
1024 atoms. Following the addition of hydrogen atoms the structural model was optimized (energy minimized) using ONIOM methods with all atoms associated with the protein backbone, and the non-heme iron atom, being held fixed. All atoms of the amino acid side chains and the incorporated quinone are unconstrained. For calculations of UQ/VK the hydrocarbon tail was modeled as a single prenyl/phytyl unit, respectively. Inclusion of further prenyl/phytyl units did not alter the calculated spectra (not shown).

The structural models for the different incorporated quinones are initially set up by simply replacing the molecular substituents of the originally incorporated UQ species. So, the $\mathrm{C}=\mathrm{O}$ groups of the different quinones incorporated will initially have the same orientation and position to that found for UQ in the $\mathrm{Q}_{\mathrm{A}}$ binding site. DMNQ and VK structures were constructed starting from the UQ structure, by replacing the methoxy groups with the NQ aromatic ring, without alteration of the quinone ring (Figure $2 \mathrm{~F}$ ). This orientation of the NQ ring (of DMNQ and VK) was chosen as previous docking calculations have suggested it is the most favorable (Hucke et al., 2002).

\section{CALCULATIONS}

All calculations were undertaken using Gaussian 03 (Frisch et al., 2004) software. For calculation of UQ molecules in the gas phase, and for the QM part of ONIOM calculations, molecular geometry optimizations and harmonic vibrational frequency calculations were undertaken using hybrid DFT methods, employing the B3LYP functional and the $6-31+\mathrm{G}(\mathrm{d})$ basis set. This choice of functional and basis set are appropriate for calculation of the vibrational properties of quinones (Wheeler, 2001; Bandaranayake et al., 2006). The MM part of the ONIOM calculation is undertaken using the AMBER force field (Case et al., 2005). Following ONIOM geometry optimization of the structural model, the optimized quinone molecule from the model is considered separately for vibrational frequency calculations.

\section{NORMAL MODE ASSESSMENT}

Assignment of calculated vibrational frequencies to molecular groups is based on a consideration of the calculated atomic displacements (in Cartesian coordinates) associated with the normal modes. These atomic displacements can be animated using software (GaussView4), and the molecular groups that most prominently contribute to the normal modes can be assessed visually [see Figure 2 in Bandaranayake et al. (2006)]. In addition, potential energy distributions (PEDs) of the normal modes are calculated using the freeware GAR2PED (Martin and Van Alsenoy, 1995). For the various quinones in the $\mathrm{Q}_{\mathrm{A}}$ binding site we calculate both vibrational mode frequencies and intensities. With both the frequency and intensity information "stick spectra" can be constructed. These stick spectra are representative of IR absorption spectra, as described previously (Bandaranayake et al., 2006; Parameswaran et al., 2008; Lamichhane et al., 2010). The calculated stick spectra are convolved with a Gaussian function with half-width of $4 \mathrm{~cm}^{-1}$ to produce more realistic looking IR absorption spectra (Bandaranayake et al., 2006; Parameswaran et al., 2008; Lamichhane et al., 2010).

\section{RESULTS}

\section{UQ STRUCTURE AND NUMBERING}

Figure 1 shows the structure and numbering scheme used here for $\mathrm{UQ}_{n}, \mathrm{MQ}_{0}, \mathrm{DQ}, \mathrm{DMNQ}$, and VK. NQ's generally have a different numbering scheme. We have applied the UQ numbering scheme to DMNQ and VK for the sake of easy comparison. Figure 2 shows a picture of (A) DMNQ, (B) VK, (C) $\mathrm{MQ}_{0}$, and (D) $\mathrm{UQ}_{1}$ in the $\mathrm{Q}_{\mathrm{A}}$ binding site along with the two H-bonding amino acids. The structures shown are after geometry optimization using ONIOM methods. Possible hydrogen bonds (or ligand to the non-heme iron atom) are indicated by dotted lines.

To gain a better sense of the relative orientation of the different quinones in the $\mathrm{Q}_{\mathrm{A}}$ binding site Figure 2 also shows the (E) DMNQ/DQ and (F) DMNQ/UQ structures from two ONIOM calculations overlapped. These overlapped structures are created by considering the (fixed) atoms of the protein backbone. Figures 2E,F indicates that the side chains of HisM219 and AlaM260 are unaltered when a different quinone is incorporated into the binding site.

Table 1 lists several bond lengths and bond angles derived from our ONIOM calculated optimized geometries of the various quinones in the $\mathrm{Q}_{\mathrm{A}}$ binding site. For comparison, Table 1 also lists corresponding bond lengths and angles derived from our DFT calculated optimized geometries of the various quinones in the gas phase. Table 1 also list results obtained from previous QM/MM calculations (Sinnecker et al., 2006), and data taken from the 1AIJ crystal structure (Stowell et al., 1997).

Table 1 list the three distances associated with the peptide or imidazole $\mathrm{H}$-bond to the carbonyl oxygen atoms of the quinone ( $\mathrm{N}-\mathrm{H}, \mathrm{NH}-\mathrm{O}$ and $\mathrm{N}-\mathrm{O}$ distances). These distances completely determine the $\mathrm{N}-\mathrm{H}-\mathrm{O} \mathrm{H}$-bond geometry. Associated angles are also listed in Table 1.

For $\mathrm{UQ}_{10}$ in the $\mathrm{Q}_{\mathrm{A}}$ site the 1AIJ crystal structure (Stowell et al., 1997) indicates that the $\mathrm{C}_{1}=\mathrm{O}$ bond is marginally longer than the $\mathrm{C}_{4}=\mathrm{O}$ bond. ( 1.234 vs. $1.232 \AA$ ). In contrast, from ONIOM calculations of all the quinones listed in Table 1 the $\mathrm{C}_{1}=\mathrm{O}$ bond is shorter than the $\mathrm{C}_{4}=\mathrm{O}$ bond.

In gas phase calculations the $\mathrm{C}_{1}=\mathrm{O}$ and $\mathrm{C}_{4}=\mathrm{O}$ bond lengths are shorter than that found in ONIOM calculations (except the $\mathrm{C}_{1}=\mathrm{O}$ of $\mathrm{DQ}$ ). This lengthening of the $\mathrm{C}=\mathrm{O}$ bonds of the quinones in the $\mathrm{Q}_{\mathrm{A}}$ binding site is related to hydrogen bonding and other electrostatic interactions of the pigment with the protein environment.

For $\mathrm{UQ}_{1}$ and $\mathrm{MQ}_{0}$ the $\mathrm{C}_{1}=\mathrm{O}$ bond is shorter than the $\mathrm{C}_{4}=\mathrm{O}$ bond in both ONIOM and gas phase calculations. In gas phase calculations this difference in $\mathrm{C}_{1}=\mathrm{O}$ and $\mathrm{C}_{4}=\mathrm{O}$ bond lengths of $\mathrm{UQ}_{1}$ and $\mathrm{MQ}_{0}$ must relate to the differing orientations of the $\mathrm{C}_{2}$ and $\mathrm{C}_{3}$ methoxy groups. The ONIOM calculated $\mathrm{C}_{2}$ and $\mathrm{C}_{3}$ methoxy group dihedral angles for $\mathrm{UQ}_{1}$ are -25.3 and $150.5^{\circ}$ (Table 1). Similar angles are calculated for $\mathrm{MQ}_{0}$. The calculated dihedral angles for $\mathrm{UQ}_{1}$ in the gas phase, and the observed angles for $\mathrm{UQ}_{10}$ in the $\mathrm{Q}_{\mathrm{A}}$ binding site (from the crystal structure) are within $32^{\circ}$ of that calculated for $\mathrm{UQ}_{1}$ using ONIOM methods.

For $\mathrm{UQ}_{10}$ in the $\mathrm{Q}_{\mathrm{A}}$ site the crystal structure indicates that the $\mathrm{C}_{2}=\mathrm{C}_{3}$ bond is shorter than the $\mathrm{C}_{5}=\mathrm{C}_{6}$ bond. ( 1.404 vs. $1.419 \AA$ ). In contrast, for all quinones except $\mathrm{DQ}$, in both ONIOM and gas phase calculations the $\mathrm{C}_{2}=\mathrm{C}_{3}$ bond is longer than the $\mathrm{C}_{5}=\mathrm{C}_{6}$ 


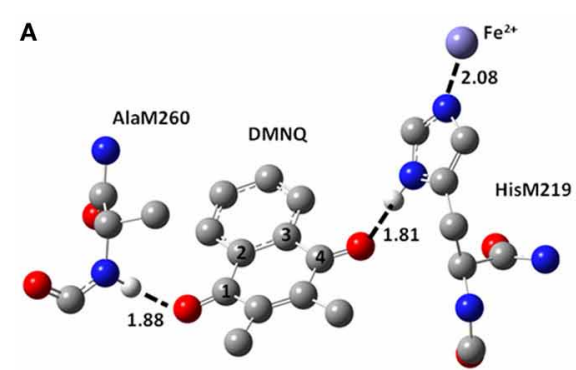

C

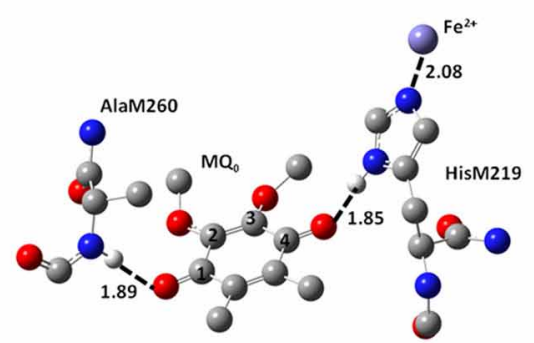

E

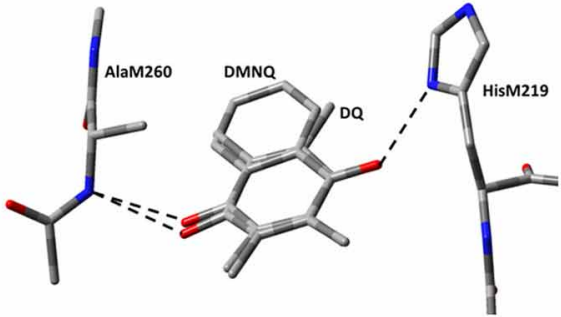

FIGURE 2 | Ball and stick representation of the calculated structure of (A) DMNQ, (B) VK, (C) $\mathrm{MQ}_{0}$ and (D) $\cup \mathrm{Q}_{1}$ in the $\mathrm{Q}_{A}$ binding site in PBRCs from $\boldsymbol{R} \boldsymbol{b}$. sphaeroides. Structure shown is after geometry optimization using ONIOM methods. Possible H-bonds are shown (dotted). Hydrogen atoms, except the ones involved in $\mathrm{H}$-bonding, have been
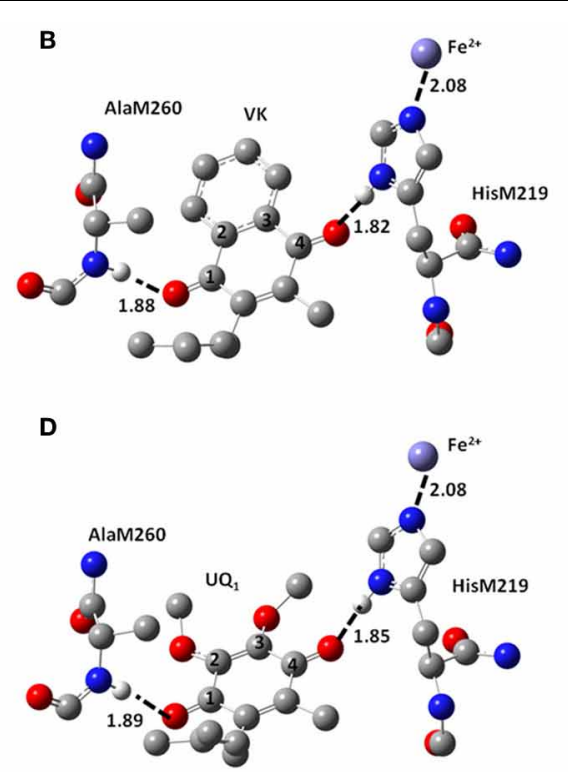

$\mathbf{F}$

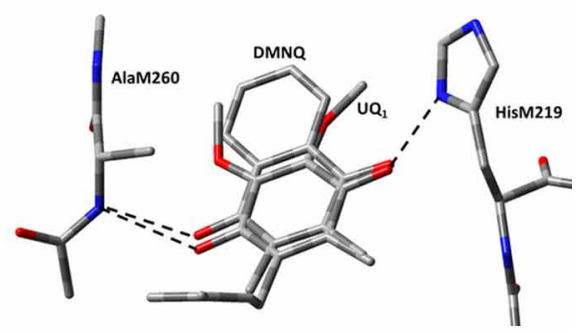

omitted. Distances quoted are in $\AA$. (E,F) Overlap of structures obtained from ONIOM calculations for (E) DMNQ and DQ and (F) DMNQ and $\cup Q_{1}$. Overlap is based on using the (fixed) backbone atoms of HisM219 and AlaM260. The amino acid side chains are virtually unaltered in the structures shown. bond. For VK and DMNQ the calculated $\mathrm{C}_{2}=\mathrm{C}_{3}$ and $\mathrm{C}_{5}=\mathrm{C}_{6}$ bond lengths are considerably different.

For $\mathrm{UQ}_{1}$ and $\mathrm{VK}$ the hydrocarbon chain attached at $\mathrm{C}_{6}$ makes a distinct "kink" after the first carbon atom (Figures 2B,D). The $\mathrm{C}-\mathrm{C}-\mathrm{C}$ bond angle is $112-115^{\circ}$ for both quinones in both the ONIOM and gas phase calculations. The calculated angles are virtually the same as that found in the crystal structure. Given these similarities (between the ONIOM and gas phase calculations for both $\mathrm{UQ}_{1}$ and $\mathrm{VK}$, as well as between calculation and experiment) the suggestion is that the protein environment does not constrain the orientation of the quinone ring relative to the $\mathrm{C}_{6}$ hydrocarbon chain.

Figure 3A shows ONIOM calculated ${ }^{18} \mathrm{O}$ isotope edited difference spectra for neutral VK and DMNQ. Figure 3D shows corresponding DFT calculated spectra for VK and DMNQ in the gas phase. Experimental spectra are also shown (Figures 3B,C) for comparison. Positive/negative bands in the isotope edited spectra are due to the unlabeled $/{ }^{18} \mathrm{O}$ labeled quinone species, respectively. The ONIOM calculated spectra clearly better describe the experimental spectra. Calculations including the protein environment appear to be necessary in order to adequately simulate the experimental spectra.

In the DFT calculated ${ }^{18} \mathrm{O}$ isotope edited spectrum for DMNQ/VK in the gas phase (Figure 3D) the antisymmetric vibration of both $\mathrm{C}=\mathrm{O}$ groups gives rise to the band at $\sim 1654 \mathrm{~cm}^{-1}$ (Figure 3D), which downshifts $30 \mathrm{~cm}^{-1}$ upon ${ }^{18} \mathrm{O}$ labeling (Bandaranayake et al., 2006). The calculated isotopeedited gas phase spectrum is in excellent agreement with the experimental spectrum for DMNQ in solution (Breton et al., 1994a).

Figure 3 shows that except for a small frequency shift in some of the modes, the calculated spectra for DMNQ and VK are virtually the same. Replacement of the methyl group at $\mathrm{C}_{6}$ with an isoprene unit therefore, has no influence on the calculated spectra.

The normal modes (frequencies and intensities) that give rise to the various bands in the ONIOM calculated ${ }^{18} \mathrm{O}$ isotope edited spectra of DMNQ and VK are listed in Table 2. The PEDs, which quantify to what extent various internal coordinates contribute to the normal modes, are also listed in Table 2. Results for DMNQ 
Table 1 | Comparison of bond lengths and angles derived from the ONIOM calculated (O) and gas phase calculated (GP) optimized geometry of neutral $\mathrm{UQ}_{1}, \mathrm{MO}_{0}, \mathrm{DQ}, \mathrm{VK}$, and DMNO.

\begin{tabular}{|c|c|c|c|c|c|c|c|c|c|c|c|c|}
\hline & x-ray & \multicolumn{2}{|c|}{ UQ1 } & \multicolumn{2}{|c|}{ MQo } & \multicolumn{2}{|c|}{ DQ } & \multicolumn{2}{|c|}{$\mathbf{V K}_{1}$} & \multicolumn{2}{|c|}{ DMNQ } & $\frac{\text { Ref }}{\text { U01 }}$ \\
\hline $\mathrm{C}_{1}=\mathrm{O}$ & 1.234 & 1.227 & 1.223 & 1.227 & 1.223 & 1.232 & 1.230 & 1.233 & 1.229 & 1.232 & 1.229 & 1.235 \\
\hline $\mathrm{C}_{4}=\mathrm{O}$ & 1.232 & 1.238 & 1.231 & 1.238 & 1.231 & 1.236 & 1.231 & 1.236 & 1.229 & 1.236 & 1.229 & 1.237 \\
\hline$C_{2}=C_{3}$ & 1.404 & 1.366 & 1.364 & 1.367 & 1.364 & 1.355 & 1.355 & 1.405 & 1.405 & 1.406 & 1.405 & \\
\hline $\mathrm{C}_{5}=\mathrm{C}_{6}$ & 1.419 & 1.354 & 1.354 & 1.354 & 1.354 & 1.357 & 1.355 & 1.363 & 1.361 & 1.362 & 1.360 & \\
\hline $\mathrm{N}-\mathrm{H}$ & 1.014 & 1.014 & & 1.014 & & 1.013 & & 1.013 & & 1.013 & & 1.014 \\
\hline $\mathrm{N}-\mathrm{H}-\mathrm{O}$ & 1.912 & 1.894 & & 1.886 & & 1.907 & & 1.883 & & 1.883 & & $1.94 \pm 0.11$ \\
\hline$\angle \mathrm{N}-\mathrm{H}-\mathrm{O}$ & 150.2 & 153.3 & & 156.7 & & 164.4 & & 159.9 & & 166.7 & & $147 \pm 7$ \\
\hline$\angle \mathrm{C}-\mathrm{O}-\mathrm{N}$ & 131.5 & 127.0 & & 125.9 & & 127.4 & & 125.7 & & 124.1 & & \\
\hline$\angle \mathrm{C}-\mathrm{O}-\mathrm{H}$ & 133.4 & 128.7 & & 128.3 & & 132.6 & & 128.0 & & 128.1 & & \\
\hline $\mathrm{N}-\mathrm{H}-\mathrm{O}$ & 1.788 & 1.849 & & 1.845 & & 1.810 & & 1.815 & & 1.812 & & $1.79 \pm 0.14$ \\
\hline$\angle-\mathrm{N}-\mathrm{H}-\mathrm{O}$ & 166.2 & 175.8 & & 177.7 & & 178.8 & & 174.3 & & 178.2 & & $170 \pm 6$ \\
\hline$\angle \mathrm{C}-\mathrm{O}-\mathrm{N}$ & 138.4 & 140.1 & & 139.7 & & 137.4 & & 138.4 & & 137.8 & & \\
\hline$\angle \mathrm{C}-\mathrm{O}-\mathrm{H}$ & 140.6 & 139.4 & & 139.2 & & 137.4 & & 137.5 & & 137.3 & & \\
\hline $\mathrm{C}_{4}=\mathrm{O}-\mathrm{Fe}$ & 6.832 & 6.744 & & 6.715 & & 6.627 & & 6.692 & & 6.637 & & \\
\hline$\angle$ Tail & 113.0 & 114.9 & 111.7 & & & & & 114.7 & 111.6 & & & \\
\hline $\mathrm{C}_{2}$-dihedral & -57.1 & -25.3 & -8.9 & -26.5 & -10.1 & & & & & & & \\
\hline $\mathrm{C}_{3}$-dihedral & 109.5 & 150.5 & 123.6 & 150.6 & 123.1 & & & & & & & \\
\hline
\end{tabular}

Bond lengths and angles from the $1 \mathrm{AlJ}$ crystal structure (Stowell et al., 1997) are also listed. Distances are in $\AA$ and angles are in degrees. The $C_{2}$ and $C_{3}$ methoxy group dihedral angles are defined as the $\mathrm{C}_{3}-\mathrm{C}_{2}-\mathrm{O}-\mathrm{CH}_{3}$ and $\mathrm{C}_{2}-\mathrm{C}_{3}-\mathrm{O}-\mathrm{CH}_{3}$ dihedral angles from Sinnecker et al. (2006).

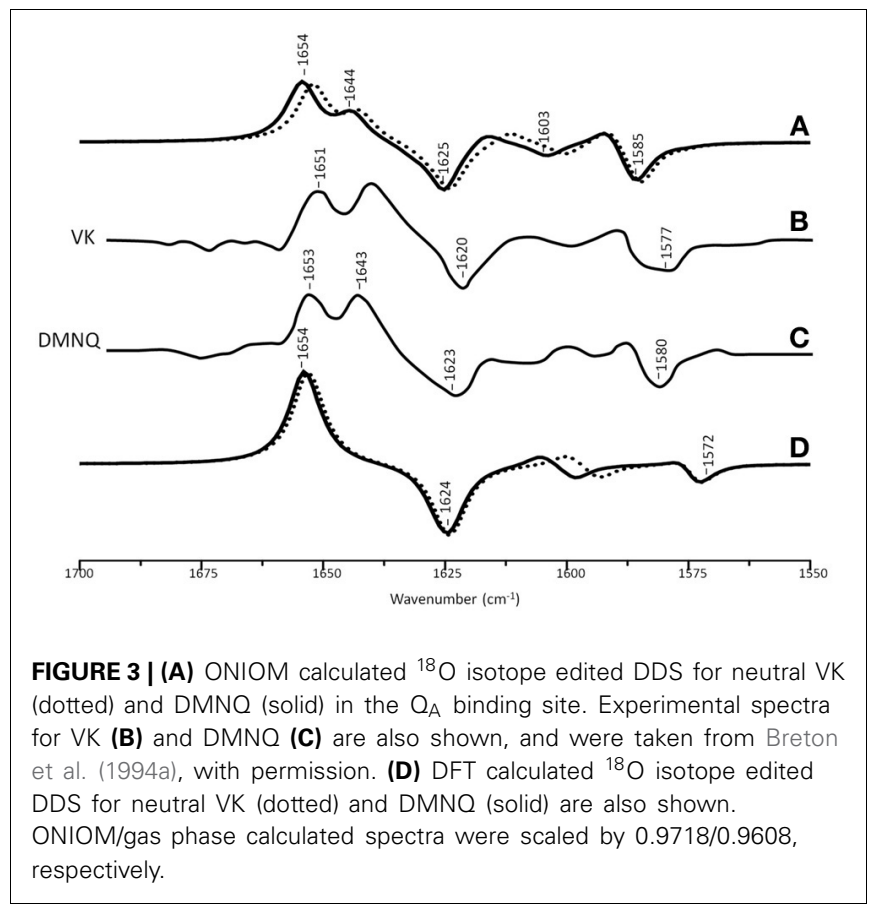

and VK are very similar. Below we will discuss calculated data obtained for DMNQ with the recognition that very similar results and conclusions also apply to VK.

In the ONIOM calculated ${ }^{18} \mathrm{O}$ isotope edited spectra for DMNQ the two bands at 1654 and $1644 \mathrm{~cm}^{-1}$ are due to $\mathrm{C}_{1}=\mathrm{O}$ and $\mathrm{C}_{4}=\mathrm{O}$ stretching vibrations, respectively (Table 2 ). These bands almost certainly correspond to the at 1653 and $1643 \mathrm{~cm}^{-1}$ bands in the experimental spectrum (Figure 3C). So our calculations predict that the 1653 and $1643 \mathrm{~cm}^{-1}$ bands in the experimental spectrum are due to $\mathrm{C}_{1}=\mathrm{O}$ and $\mathrm{C}_{4}=\mathrm{O}$ stretching vibrations, respectively. This is in fact the first direct evidence that the 1653 and $1643 \mathrm{~cm}^{-1}$ bands in the experimental spectrum are due to $\mathrm{C}_{1}=\mathrm{O}$ and $\mathrm{C}_{4}=\mathrm{O}$ stretching vibrations. A direct assignment has never been made because specific ${ }^{13} \mathrm{C}_{1}$ and ${ }^{13} \mathrm{C}_{4}$ isotopic labeled VK or DMNQ has never been incorporated into the $\mathrm{Q}_{\mathrm{A}}$ binding site in PBRCs.

In contrast to the observation of two separate $\mathrm{C}=\mathrm{O}$ modes in ONIOM calculations, in gas phase calculations the two $\mathrm{C}=\mathrm{O}$ modes of DMNQ are anti-symmetrically coupled (Bandaranayake et al., 2006), giving rise to a single intense band at $1654 \mathrm{~cm}^{-1}$ (Figure 3D).

In ONIOM calculations it is found that upon ${ }^{18} \mathrm{O}$ labeling the $\mathrm{C}_{1}=\mathrm{O}$ and $\mathrm{C}_{4}=\mathrm{O}$ modes of DMNQ downshift 23 and $19 \mathrm{~cm}^{-1}$, 
Table 2 | Normal mode frequencies (in $\mathrm{cm}^{-1}$ ), intensities (in $\mathrm{km} / \mathrm{mol}$ ) and PEDs (in \%) calculated using ONIOM methods for unlabeled and ${ }^{18} \mathrm{O}$ labeled neutral DMNQ, VK, DQ, $\mathrm{MQ}_{0}$, and $\mathrm{UQ}_{1}$.

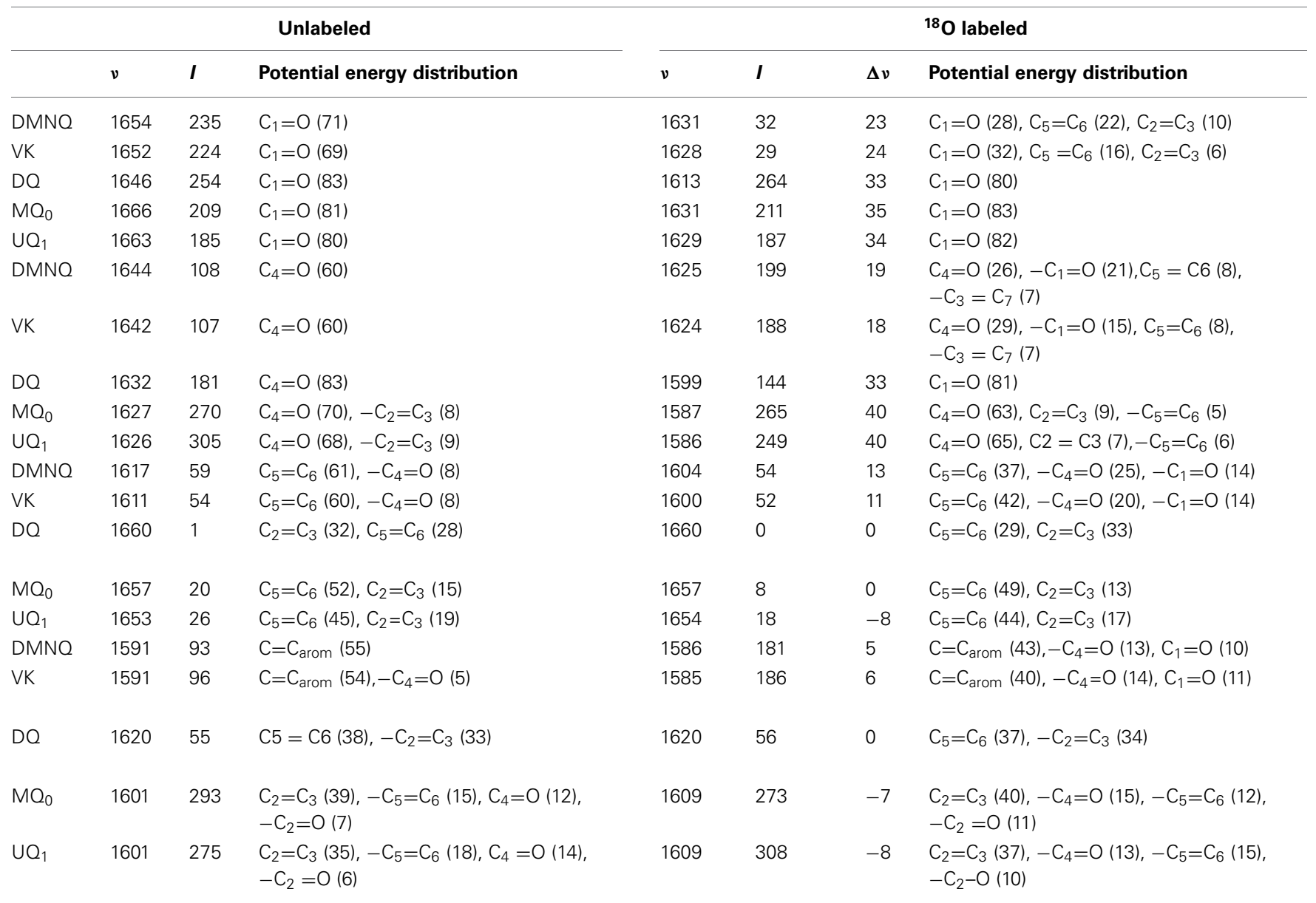

Frequency shifts upon ${ }^{18} \mathrm{O}$ labeling are also listed. Negative signs in the PEDs refer to the relative phase of vibration of the internal coordinates. Only internal coordinates that contribute at least $5 \%$ are shown. Mode frequencies were scaled by 0.9718 .

to 1631 and $1625 \mathrm{~cm}^{-1}$, respectively (Table 2). Upon ${ }^{18} \mathrm{O}$ labeling the $1625 \mathrm{~cm}^{-1}$ mode is more than six times more intense than the $1631 \mathrm{~cm}^{-1}$ mode. The $1625 \mathrm{~cm}^{-1}$ mode in ${ }^{18} \mathrm{O}$ labeled DMNQ is due mainly to the antisymmetric coupled vibration of both $\mathrm{C}=\mathrm{O}$ groups. That is, two separate $\mathrm{C}=\mathrm{O}$ modes of unlabeled DMNQ couple upon ${ }^{18} \mathrm{O}$ labeling. This behavior is not predicted based upon consideration of the experimental spectra, where it is "assumed" that the two $\mathrm{C}=\mathrm{O}$ modes remain separate upon ${ }^{18} \mathrm{O}$ labeling (Breton et al., 1994b; Breton, 1997).

$\mathrm{A} C \mathrm{C}=\mathrm{C}$ mode of the quinone ring of $\mathrm{DMNQ}$ is found at $1617 \mathrm{~cm}^{-1}$. This quinonic $\mathrm{C}=\mathrm{C}$ mode downshifts $13 \mathrm{~cm}^{-1}$, to $1604 \mathrm{~cm}^{-1}$, upon ${ }^{18} \mathrm{O}$ labeling, with little change in intensity. The $1604 \mathrm{~cm}^{-1}$ mode composition in ${ }^{18} \mathrm{O}$ labeled DMNQ displays considerable mixing of the $\mathrm{C}=\mathrm{O}$ and $\mathrm{C}=\mathrm{C}$ modes (the $\mathrm{C}=\mathrm{O}$ modes account for $39 \%$ of the $\mathrm{PED})$. This behavior might be expected given that the $\mathrm{C}=\mathrm{O}$ and $\mathrm{C}=\mathrm{C}$ modes are closer in frequency upon ${ }^{18} \mathrm{O}$ labeling.

$\mathrm{A} \mathrm{C}=\mathrm{C}$ mode of the aromatic ring of DMNQ occurs at $1591 \mathrm{~cm}^{-1}$. This aromatic $\mathrm{C}=\mathrm{C}$ mode downshifts $5 \mathrm{~cm}^{-1}$ to $1586 \mathrm{~cm}^{-1}$ upon ${ }^{18} \mathrm{O}$ labeling. The $1586 \mathrm{~cm}^{-1}$ mode in ${ }^{18} \mathrm{O}$ labeled DMNQ displays some mixing with $\mathrm{C}=\mathrm{O}$ modes $(23 \%)$, and the intensity of the aromatic $\mathrm{C}=\mathrm{C}$ mode nearly doubles upon ${ }^{18} \mathrm{O}$ labeling. The calculated $\mathrm{C}=\mathrm{C}$ normal modes and their interpretation in terms of internal coordinates, as well as the calculated ${ }^{18} \mathrm{O}$ induced frequency shifts are similar to that suggested on the basis of the experimental spectra (Breton et al., 1994a).

Figure 4A shows ONIOM calculated ${ }^{18} \mathrm{O}$ isotope edited IR difference spectra for neutral DQ in the $\mathrm{Q}_{\mathrm{A}}$ binding site. Figure 4C shows the corresponding DFT calculated spectrum for DQ in the gas phase. The experimental spectrum is shown in Figure 4B. Again, the ONIOM calculated spectrum agrees well with the experimental spectrum while the calculated gas phase spectrum does not. The ONIOM calculated normal modes (frequencies and intensities) that give rise to the bands in the ${ }^{18} \mathrm{O}$ isotope edited spectrum for DQ, as well as the PEDs, are listed in Table 2.

In the ONIOM calculated ${ }^{18} \mathrm{O}$ isotope edited spectrum for DQ the two bands at 1646 and $1632 \mathrm{~cm}^{-1}$ are due to $\mathrm{C}_{1}=\mathrm{O}$ and $\mathrm{C}_{4}=\mathrm{O}$ stretching vibrations, respectively (Table 2). Upon ${ }^{18} \mathrm{O}$ labeling the $\mathrm{C}_{4}=\mathrm{O}$ and $\mathrm{C}_{1}=\mathrm{O}$ modes both downshift $33 \mathrm{~cm}^{-1}$ with little change in mode intensities (Table 2). This $33 \mathrm{~cm}^{-1}$ 


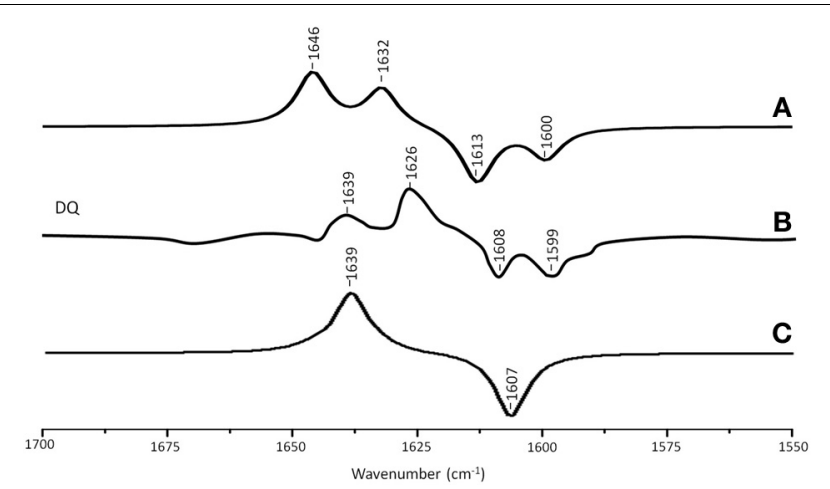

FIGURE 4 | (A) ONIOM calculated ${ }^{18} \mathrm{O}$ isotope edited DDS for neutral DO in the $\mathrm{Q}_{A}$ binding site. Experimental spectra are shown in (B), and were taken from Breton et al. (1994a) with permission. (C) DFT calculated ${ }^{18} \mathrm{O}$ isotope edited DDS for neutral DQ. ONIOM and gas phase calculated spectra were scaled by 0.9718 and 0.9608 , respectively.

downshift is large compared to that calculated for DMNQ (19$23 \mathrm{~cm}^{-1}$ ). For DQ, the ONIOM calculated mode composition is virtually unchanged upon ${ }^{18} \mathrm{O}$ labeling. This is also markedly different to that calculated for DMNQ. The normal modes that give rise to the isotope edited spectra of DQ and DMNQ in the gas phase are very similar, so replacing the methyl groups of DQ with the aromatic ring of DMNQ in the $\mathrm{Q}_{\mathrm{A}}$ binding site leads to an alteration in the electronic structure of the quinone ring. This modification is not obvious given the similar orientation of DQ and DMNQ in the $\mathrm{Q}_{\mathrm{A}}$ binding site (Figure 2E).

In the DFT calculated ${ }^{18} \mathrm{O}$ isotope edited spectrum for DQ in the gas phase, the two $\mathrm{C}=\mathrm{O}$ modes are strongly coupled, and give rise to the band at $1639 \mathrm{~cm}^{-1}$ in Figure 4C. The calculated gas phase spectrum is in line with the experimental FTIR spectrum for DQ in solution (Breton et al., 1994a).

From ONIOM calculations for $\mathrm{DQ}, \mathrm{C}=\mathrm{C}$ modes do not couple with the $\mathrm{C}=\mathrm{O}$ modes. The $\mathrm{C}_{2}=\mathrm{C}_{3}$ and $\mathrm{C}_{5}=\mathrm{C}_{6}$ groups couple to produce in phase and out of phase vibrational modes. The in phase mode has negligible IR intensity. The out of phase $\mathrm{C}=\mathrm{C}$ mode is calculated to be at $1620 \mathrm{~cm}^{-1}$. This $\mathrm{C}=\mathrm{C}$ mode is virtually unaltered in frequency, intensity, and mode composition upon ${ }^{18} \mathrm{O}$ labeling (Table 2).

Figure 5A shows ONIOM calculated ${ }^{18} \mathrm{O}$ isotope edited IR spectra for neutral $\mathrm{MQ}_{0}$ (solid) and $\mathrm{UQ}_{1}$ (dotted) in the $\mathrm{Q}_{\mathrm{A}}$ binding site. Figure 5D shows DFT calculated spectra for $\mathrm{MQ}_{0}$ and $\mathrm{UQ}_{1}$ in the gas phase. The experimental spectra for $\mathrm{UQ}_{1}$ and $\mathrm{MQ}_{0}$ are shown in Figures 5B,C, respectively. The normal modes (frequencies and intensities) that give rise to the various bands in the ONIOM calculated spectra, as well as the PEDs, are listed in Table 2. The data for $\mathrm{UQ}_{1}$ has been presented previously (Lamichhane and Hastings, 2011), and we show here that very similar spectra are calculated for both $\mathrm{MQ}_{0}$ and $\mathrm{UQ}_{1}$. Replacement of an isoprene unit at $\mathrm{C}_{6}$ with a methyl group does not greatly alter the calculated spectra.

In the ONIOM calculated ${ }^{18} \mathrm{O}$ isotope edited spectra for neutral $\mathrm{MQ}_{0}$ the two bands at 1666 and $1627 \mathrm{~cm}^{-1}$ (Figure 5C) are due to $\mathrm{C}_{1}=\mathrm{O}$ and $\mathrm{C}_{4}=\mathrm{O}$ stretching vibrations, respectively

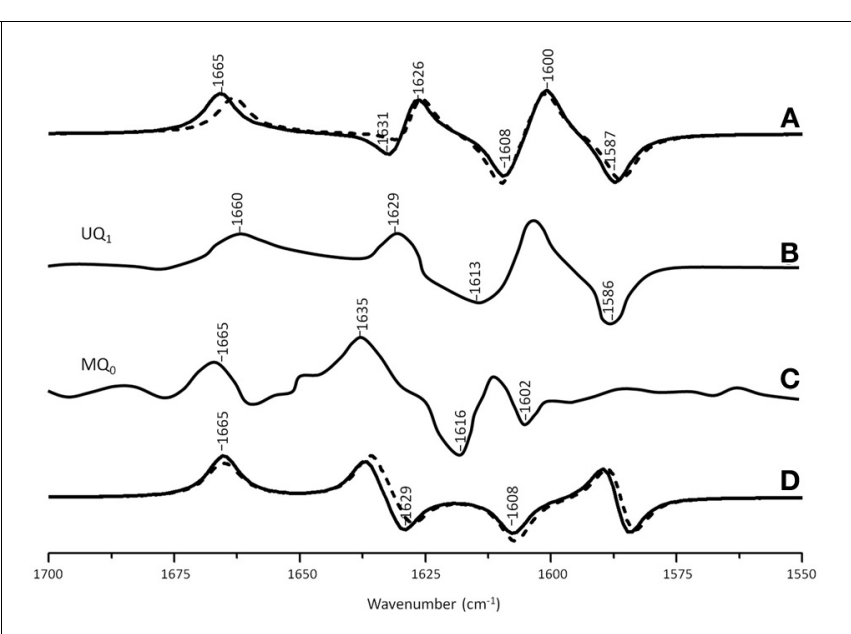

FIGURE 5 | (A) ONIOM calculated ${ }^{18} \mathrm{O}$ isotope edited DDS for neutral $\mathrm{MQ}_{0}$ (solid) and $\cup Q_{1}$ (dotted) in the $\mathrm{Q}_{A}$ binding site. Experimental spectrum for (B) $\mathrm{MQ}_{0}$ and (C) $\cup Q_{1}$ are also shown, and were taken from Breton et al. (1994a) with permission. (D) DFT calculated ${ }^{18} \mathrm{O}$ isotope edited DDS for neutral $\mathrm{MQ}_{0}$ (solid) and $\mathrm{UQ}_{1}$ (dotted). ONIOM and gas phase calculated spectra were scaled by 0.9718 and 0.9608 , respectively.

(Table 2). Upon ${ }^{18} \mathrm{O}$ labeling the $\mathrm{C}_{1}=\mathrm{O}$ and $\mathrm{C}_{4}=\mathrm{O}$ modes downshift 35 and $40 \mathrm{~cm}^{-1}$, respectively (Table 2 ). The mode intensities and composition are little altered by ${ }^{18} \mathrm{O}$ labeling. The $\mathrm{C}=\mathrm{C}$ mode of $\mathrm{MQ}_{0} / \mathrm{UQ}_{1}$ at $1601 \mathrm{~cm}^{-1}$ up-shifts $8 / 7 \mathrm{~cm}^{-1}$ upon ${ }^{18} \mathrm{O}$ labeling (Table 2). An explanation for this ${ }^{18} \mathrm{O}$ induced frequency upshift has been presented (Lamichhane and Hastings, 2011).

In the DFT calculated ${ }^{18} \mathrm{O}$ isotope edited spectra for $\mathrm{UQ}_{1} / \mathrm{MQ}_{0}$ in the gas phase, the two $\mathrm{C}=\mathrm{O}$ modes are well separated, and give rise to bands at $\sim 1665$ and $\sim 1635 \mathrm{~cm}^{-1}$ (Figure 5D), which downshift 36 and $27 \mathrm{~cm}^{-1}$, respectively, upon ${ }^{18} \mathrm{O}$ labeling, as described previously (Lamichhane et al., 2011).

\section{DISCUSSION}

Previously we have shown that ONIOM methods can be used to calculate isotope edited difference spectra for $\mathrm{UQ}_{1}$ in the $\mathrm{Q}_{\mathrm{A}}$ binding site, and that these calculated spectra model very well the corresponding experimental spectra (Lamichhane and Hastings, 2011). Here we considerably extend these studies, and show that ONIOM calculated isotope edited spectra for different quinones in the $\mathrm{Q}_{\mathrm{A}}$ binding site model very well the corresponding experimental spectra. We further show that the calculated spectra for quinones in the gas phase are totally inappropriate for modeling the vibrational properties of quinones in the $\mathrm{Q}_{\mathrm{A}}$ binding site. This is also very likely to be the case for modeling the properties of any protein bound pigment.

Without normal mode vibrational frequency calculations interpretation of experimental spectra is limited, and here we clearly show that our computational methods lead to a greatly increased understanding of the normal modes that contribute to the bands in the experimental spectra.

In our ONIOM calculations for neutral $\mathrm{UQ}_{1}$ in the $\mathrm{Q}_{A}$ binding site we considered all amino acids included in the model only at the molecular mechanics level of computation. Previously, 
ONIOM calculations have been undertaken in order to model EPR data associated with the UQ anion in the $\mathrm{Q}_{\mathrm{A}}$ binding site (Lin and O'Malley, 2008). In these calculations key amino acids, such as HisM219 and AlaM260, were considered at the higher quantum mechanical level of calculation. Taken together these results may indicate differences in the nature of $\mathrm{H}$-bonding for the neutral and anion UQ species. Changes in H-bonding upon radical formation may be a mechanism for (de)stabilizing cofactors to fine-tune electron transfer processes in biological systems. Clearly it will be useful to undertake calculations similar to that presented here (modeling isotope edited FTIR difference spectra) for the UQ anion in the $\mathrm{Q}_{\mathrm{A}}$ binding site, and such calculations are underway in our lab. Based on the above one could argue that the methods used here, with only the quinone treated at the QM level, will be inadequate to simulate the experimental spectra associated with quinone anions in the $\mathrm{Q}_{\mathrm{A}}$ binding site. Or, for simulating the vibrational properties of quinone anions in the $\mathrm{Q}_{\mathrm{A}}$ binding site it will be necessary to treat key amino acids at a quantum mechanical level. Again, calculations are underway in our lab to test this proposal.

For the neutral state of quinones occupying the $\mathrm{Q}_{\mathrm{A}}$ binding site, calculations with the $\mathrm{H}$-bonding amino acids treated at the MM level lead to calculated spectra that are in excellent agreement with experimental spectra (Figures 3-5). Clearly, treating $\mathrm{H}$-bonding amino acids quantum mechanically will not lead to improved modeling of the experimental spectra. We have in fact undertaken calculations in which neutral UQ and the H-bonding amino acids are treated using QM, and we have found that the calculated spectra are very similar to that obtained when only neutral UQ is treated using QM (and the surrounding amino acids are treated using MM) (Zhao et al., J. Phys. Chem. B in press). Thus, it is very clear that, at least for the case of neutral quinones occupying the $\mathrm{Q}_{\mathrm{A}}$ binding site, and as far as modeling isotope edited FTIR spectra is concerned, QM/MM calculations with only the quinone treated at the QM level need to be considered.

An experimental ${ }^{18} \mathrm{O}$ isotope edited FTIR difference spectrum for UQ in the $\mathrm{Q}_{A}$ binding site is shown in Figure 5B. Three positive bands at 1660,1629 , and $1601 \mathrm{~cm}^{-1}$ are observed. By considering FTIR difference spectra obtained using PBRCs with unlabeled and specifically ${ }^{13} \mathrm{C}_{1}$ and ${ }^{13} \mathrm{C}_{4}$ labeled UQ occupying the $\mathrm{Q}_{\mathrm{A}}$ binding site, it was concluded that the 1660 and $1601 \mathrm{~cm}^{-1}$ bands are due to the $\mathrm{C}_{1}=\mathrm{O}$ and $\mathrm{C}_{4}=\mathrm{O}$ vibrations of unlabeled neutral UQ, respectively. It was also concluded that the $1628 \mathrm{~cm}^{-1}$ band is due to a UQ $\mathrm{C}=\mathrm{C}$ vibration (Breton et al., 1994c). Since the $\mathrm{C}_{4}=\mathrm{O}$ mode was so massively downshifted (from $\sim 1660 \mathrm{~cm}^{-1}$ for UQ in solvent to $1601 \mathrm{~cm}^{-1}$ for UQ in the $Q_{A}$ binding site) it was suggested that this group must be engaged in very strong hydrogen bonding, presumably with HisM219 (Figure 2) (Breton et al., 1994c). This conclusion is difficult to rationalize based on the crystal structural data and other experimental data [see Wraight and Gunner (2009) for a review]. Such a conclusion is also not supported by the data presented here. Specifically, the $\mathrm{C}_{1}=\mathrm{O}$ and $\mathrm{C}_{4}=\mathrm{O}$ modes of DMNQ and VK are found at 1653 and $1643 \mathrm{~cm}^{-1}$ (Table 2), respectively, compared to $\sim 1662 \mathrm{~cm}^{-1}$ for the coupled $\mathrm{C}=\mathrm{O}$ vibration in solution (Bandaranayake et al., 2006). Thus, the $\mathrm{C}_{1}=\mathrm{O} / \mathrm{C}_{4}=\mathrm{O}$ mode of DMNQ or VK in the $\mathrm{Q}_{\mathrm{A}}$ site is downshifted $9 / 19 \mathrm{~cm}^{-1}$, respectively, compared to that found in solution. Such shifts suggest that both $\mathrm{C}=\mathrm{O}$ modes of DMNQ or $\mathrm{VK}$ are $\mathrm{H}$-bonded in the $\mathrm{QA}_{\mathrm{A}}$ site, albeit quite weakly.

From the experimental spectrum of VK (or DMNQ) in Figure 3B two positive bands are observed at 1651 and $1640 \mathrm{~cm}^{-1}$ and one negative band at $1620 \mathrm{~cm}^{-1}$. The two $\mathrm{C}=\mathrm{O}$ modes of unlabeled VK give rise to the positive bands at 1651 and $1640 \mathrm{~cm}^{-1}$, but only a single band is observed at $1620 \mathrm{~cm}^{-1}$ upon ${ }^{18} \mathrm{O}$ labeling. Two interpretations for these observations have been proposed (Breton et al., 1994b). One suggestion is that upon ${ }^{18} \mathrm{O}$ labeling the $1640 \mathrm{~cm}^{-1}$ band downshifts to $\sim 1620 \mathrm{~cm}^{-1}$, while the $1651 \mathrm{~cm}^{-1}$ band downshifts to near $1640 \mathrm{~cm}^{-1}$ and decreases in intensity. The negative band near $1640 \mathrm{~cm}^{-1}$ due to a $\mathrm{C}={ }^{18} \mathrm{O}$ group of $\mathrm{VK}$ is then masked by the positive band (also at $1640 \mathrm{~cm}^{-1}$ ) due to the unlabeled $\mathrm{C}=\mathrm{O}$ group. A second hypothesis is that the two $\mathrm{C}=\mathrm{O}$ modes of unlabeled VK (at 1651 and $1640 \mathrm{~cm}^{-1}$ ) both downshift to $\sim 1620 \mathrm{~cm}^{-1}$ upon ${ }^{18} \mathrm{O}$ labeling. The different ${ }^{18} \mathrm{O}$ induced shifts of the two $\mathrm{C}=\mathrm{O}$ modes results from differential coupling to $\mathrm{C}=\mathrm{C}$ modes.

The calculated data presented here allow us to address which of these interpretations could be appropriate, or if either is appropriate. The ONIOM calculations show that the $\mathrm{C}_{1}=\mathrm{O}$ and $\mathrm{C}_{4}=\mathrm{O}$ modes of unlabeled $\mathrm{VK}$ occur at 1652 and $1642 \mathrm{~cm}^{-1}$, and that neither of these modes are coupled to $\mathrm{C}=\mathrm{C}$ modes (Table 2). Upon ${ }^{18} \mathrm{O}$ labeling the $\mathrm{C}_{1}=\mathrm{O} / \mathrm{C}_{4}=\mathrm{O}$ mode downshifts $24 / 18 \mathrm{~cm}^{-1}$, respectively. The modes of ${ }^{18} \mathrm{O}$ labeled VK also display considerable coupling with $\mathrm{C}=\mathrm{C}$ modes. Upon ${ }^{18} \mathrm{O}$ labeling the $\mathrm{C}_{1}=\mathrm{O} / \mathrm{C}_{4}=\mathrm{O}$ group couples with $\mathrm{C}=\mathrm{C}_{\text {ring }}$ in-phase/out-ofphase vibrations, respectively. Coupling of the $\mathrm{C}_{4}=\mathrm{O}$ group to the out of phase $\mathrm{C}=\mathrm{C}$ vibration leads to a large intensity enhancement, while coupling of the $\mathrm{C}_{1}=\mathrm{O}$ group to the in-phase $\mathrm{C}=\mathrm{C}$ vibration leads to a large intensity decrease (Table 2 ). So, the calculations indicate that two separate uncoupled $\mathrm{C}=\mathrm{O}$ modes in unlabeled VK give rise to predominantly a single mixed mode (that carries most of the intensity) in ${ }^{18} \mathrm{O}$ labeled VK. These calculated results indicate that neither of the two previously proposed interpretations of the experimental spectra is correct. Clearly, the calculations presented here allow a more detailed insight into the nature of the bands in the experimental isotope edited FTIR difference spectra.

Experimentally, the vibrational modes of DMNQ are at a slightly higher frequency $\left(\sim 3 \mathrm{~cm}^{-1}\right)$ than corresponding modes of VK. Presumably replacing the $\mathrm{C}_{6}$ methyl group with a phytyl unit causes this difference. Interestingly, this small frequency difference in the modes of DMNQ and VK is also found in our ONIOM calculated spectra (compare spectra in Figures 5C,B). This result is not entirely specific to the ONIOM method, however, as a small shift is also found in the gas phase calculations (Figure 3D).

The $\mathrm{C}_{1}=\mathrm{O}$ and $\mathrm{C}_{4}=\mathrm{O}$ modes of DMNQ and VK are calculated to be separated by $10 \mathrm{~cm}^{-1}$. This separation cannot be due to differences in the molecular group attached at $\mathrm{C}_{6}$. It must be due to differences in how the two $\mathrm{C}=\mathrm{O}$ groups interact with the protein. Similarly, the two $\mathrm{C}=\mathrm{O}$ modes of $\mathrm{DQ}$ are calculated to be separated by $13 \mathrm{~cm}^{-1}$, and this separation is also likely due to differences in how the two $\mathrm{C}=\mathrm{O}$ groups of $\mathrm{DQ}$ interact with the protein. 
For $\mathrm{UQ}_{1}$ (and $\mathrm{MQ}_{0}$ ) the separation of the $\mathrm{C}=\mathrm{O}$ modes is $\sim 32 \mathrm{~cm}^{-1}$ (1660-1628). Some of the differences in frequency of the $\mathrm{C}=\mathrm{O}$ modes of UQ are due to the different orientation of the methoxy groups. If we assume that protein interactions with the $\mathrm{C}=\mathrm{O}$ groups gives rise to a $13 \mathrm{~cm}^{-1}$ separation in the frequencies of the two $\mathrm{C}=\mathrm{O}$ modes then this would indicate that the difference in the orientation of the methoxy groups of UQ (or $\mathrm{MQ}_{0}$ ) gives rise to a frequency difference of $19 \mathrm{~cm}^{-1}$ for the two $\mathrm{C}=\mathrm{O}$ groups. This result is in quite good agreement with results from experimental spectra of UQ in solution, which show that the two $\mathrm{C}=\mathrm{O}$ modes are separated by $\sim 16 \mathrm{~cm}^{-1}$ (Breton et al., 1994c; Brudler et al., 1994).

Normal mode vibrational frequencies are governed by molecular bonding force constants. These force constants relate to the electronic structure of the molecule. Since the calculated and experimental spectra for DMNQ and VK are virtually the same it is concluded that the replacing the phytyl unit at $\mathrm{C}_{6}$ of $\mathrm{VK}$ with a methyl group does not appreciably perturb the electronic structure of the NQ ring. In addition, the tail does not perturb the protein in a way that significantly modifies any pigment protein interactions.

In $\mathrm{VK}$ and $\mathrm{UQ}_{1}$, the "kink" in the hydrocarbon chain after the first carbon atom is $3.1-3.2^{\circ}$ higher in ONIOM calculations compared to gas phase calculations. It seems therefore, that the hydrocarbon chain is somewhat constrained relative to the quinone ring when incorporated into the $\mathrm{Q}_{\mathrm{A}}$ binding site. It is not clear if this is a significant constraint, however. The $\mathrm{C}_{1}=\mathrm{O}$ and $\mathrm{C}_{4}=\mathrm{O}$ bonds of $\mathrm{MQ}_{0}$ and $\mathrm{UQ}_{1}$ (and of DMNQ and VK) are virtually unaltered in ONIOM calculations (Table 1). The hydrogen bond lengths for the $\mathrm{C}=\mathrm{O}$ groups are also little altered (Table 1). The distance of the $\mathrm{C}_{4}=\mathrm{O}$ oxygen to the non heme iron atom is $0.029 / 0.055 \AA$ longer for $\mathrm{UQ}_{1} / \mathrm{VK}$ compared to $\mathrm{MQ}_{0} / \mathrm{DMNQ}$, respectively, suggesting a very small change in orientation of the $\mathrm{UQ}_{1} / \mathrm{VK}$ head-group (since the iron atom is fixed) compared to $\mathrm{MQ}_{0} / \mathrm{DMNQ}$ in the $\mathrm{Q}_{\mathrm{A}}$ binding site. The hydrocarbon chain may therefore, lead to a very slight change in the orientation of the quinone ring in the $\mathrm{Q}_{\mathrm{A}}$ binding site. Figure $2 \mathrm{~F}$ shows that there is only a very small difference in the orientation of DMNQ relative to $\mathrm{UQ}_{1}$.

The experimental ${ }^{18} \mathrm{O}$ isotope edited spectra for $\mathrm{MQ}_{0}$ and $\mathrm{UQ}_{1}$ are quite different (compare Figures 5B,C). This difference cannot be modeled computationally (Figure 5A). The experimental isotope edited spectrum for $\mathrm{MQ}_{0}$ is considerably noisier than the spectrum for UQ (Breton et al., 1994a). As far as we are aware the $\mathrm{Q}_{\mathrm{A}}{ }^{-} / \mathrm{Q}_{\mathrm{A}}$ FTIR difference spectrum for RCs with $\mathrm{MQ}_{0}$ in the binding site have never been reproduced, so the accuracy of the spectrum may be somewhat questionable. On the other hand $\mathrm{MQ}_{0}$ may be able to incorporate into the $\mathrm{Q}_{\mathrm{A}}$ binding site with the methoxy groups oriented in several different ways. As described previously, each of these methoxy group conformers will have slightly different spectra (Lamichhane et al., 2010). This heterogeneity in orientation of $\mathrm{MQ}_{0}$ in the $\mathrm{Q}_{\mathrm{A}}$ binding site may be a factor that contributes to differences in the experimental spectra for $\mathrm{MQ}_{0}$ and UQ, as demonstrated in Figures 5B,C. In spite of this, there are some overall similarities in the $\mathrm{MQ}_{0}$ and $\mathrm{UQ}_{1}$ experimental spectra in Figures 5B,C. For the $\mathrm{MQ}_{0}$ spectrum positive bands are found at 1665,1631 , and $1608 \mathrm{~cm}^{-1}$. For $\mathrm{UQ}_{1}$ the bands are at 1660,1628 , and $1601 \mathrm{~cm}^{-1}$. For the $\mathrm{MQ}_{0}$ spectrum negative bands are found at 1616 and $1602 \mathrm{~cm}^{-1}$. For UQ the bands are at 1613 and $1586 \mathrm{~cm}^{-1}$.

The ONIOM calculated and experimental isotope edited spectra for VK are very similar, although the intensity ratios of the different bands do not appear to match well. For example, the intensity ratio of 1652 and $1644 \mathrm{~cm}^{-1}$ bands in the calculated spectrum (Figure 3A, dotted) is $\sim 2.1$, compared to a ratio of $\sim 0.95$ in the experimental spectrum. To investigate this further we have also calculated the ${ }^{13} \mathrm{C}$ isotope edited spectrum for $\mathrm{VK}$ in the $\mathrm{Q}_{\mathrm{A}}$ binding site (Figure 6A) (global ${ }^{13} \mathrm{C}$ labeling of $\mathrm{VK}$ ), and compared it to the corresponding experimental spectrum (Figure 6B). For completeness the calculated ${ }^{13} \mathrm{C}$ isotope edited spectrum for VK in the gas phase is shown in Figure 6C. Again, it is evident that the calculated gas phase spectrum in no way resembles the experimental spectrum (compare Figures 6B,C). The normal modes (frequencies, intensities, and PEDs) that give rise to the various bands in the ONIOM calculated ${ }^{13} \mathrm{C}$ isotope edited spectra of VK in Figure 6A are listed in Table 3.

Notice that the ONIOM calculation predicts that the two $\mathrm{C}=\mathrm{O}$ modes remain completely separate (do not mix) upon ${ }^{13} \mathrm{C}$ labeling (Table 3 ), which is unlike the behavior observed for the $\mathrm{C}=\mathrm{O}$ modes upon ${ }^{18} \mathrm{O}$ labeling (see above). Also notice that in the experimental isotope edited spectrum (Figure 6B) the $1640 \mathrm{~cm}^{-1}$ band is now considerably more intense than the $1651 \mathrm{~cm}^{-1}$ band, whereas in the calculated spectrum the higher frequency band is considerably more intense. The origin of these mode intensity differences are not entirely clear and are currently being investigated by considering calculations associated with $\mathrm{VK}$ in the presence of various types of $\mathrm{H}$-bonding molecules.

\section{CONCLUSIONS}

We have shown that ONIOM type QM/MM calculations can be used to model experimental isotope edited FTIR difference

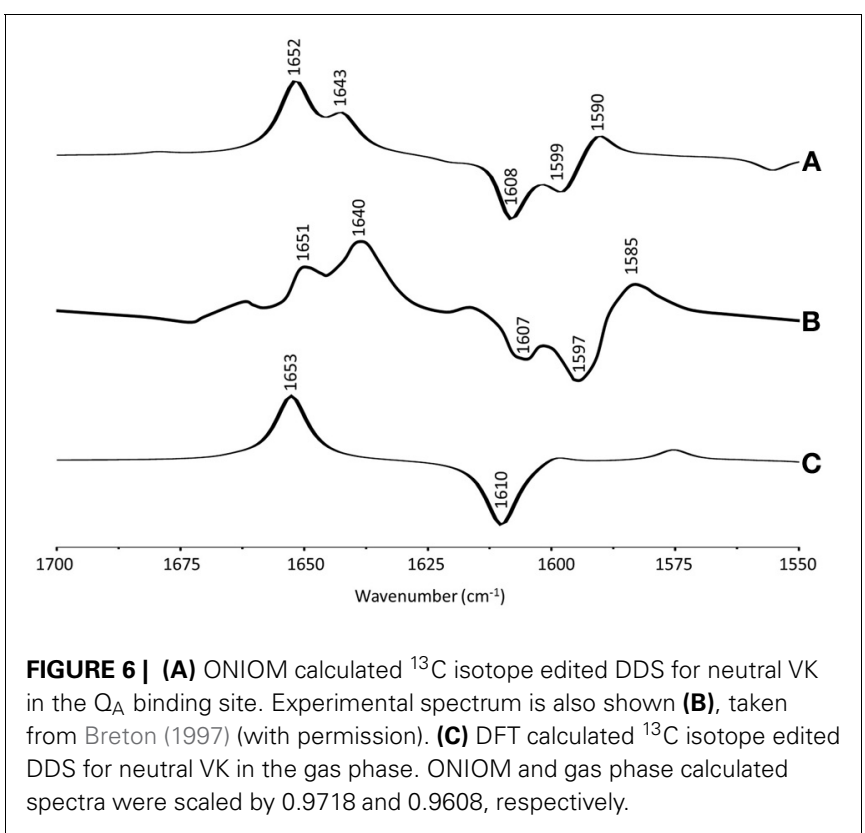


Table 3 | Normal mode frequencies (in $\mathrm{cm}^{-1}$ ), intensities (in $\mathrm{km} / \mathrm{mol}$ ) and PEDs (in \%) calculated using ONIOM methods for unlabeled and ${ }^{13} \mathrm{C}$ labeled neutral VK.

\begin{tabular}{|c|c|c|c|c|c|c|c|}
\hline \multicolumn{4}{|c|}{ Unlabeled } & \multicolumn{4}{|c|}{${ }^{13} \mathrm{C}$ labeled } \\
\hline & $v$ & $I$ & Potential energy distribution & $v$ & I & $\Delta v$ & Potential energy distribution \\
\hline \multirow[t]{4}{*}{ VK } & 1652 & 224 & $\mathrm{C}_{1}=\mathrm{O}(69)$ & 1609 & 227 & 43 & $\mathrm{C} 1=\mathrm{O}(73)$ \\
\hline & 1642 & 107 & $\mathrm{C}_{4}=\mathrm{O}(60)$ & 1598 & 116 & 44 & $\mathrm{C} 4=\mathrm{O}(70)$ \\
\hline & 1611 & 54 & $\mathrm{C}_{5}=\mathrm{C}_{6}=(60),-\mathrm{C}_{4}=\mathrm{O}(8)$ & 1555 & 43 & 56 & $\mathrm{C}_{5}=\mathrm{C}_{6}(57)$ \\
\hline & 1591 & 96 & $\mathrm{C}=\mathrm{C}_{\text {arom }}(54),-\mathrm{C}_{4}=\mathrm{O}$ & 1537 & 67 & 54 & $\mathrm{C}=\mathrm{C}_{\text {arom }}$ (55) \\
\hline
\end{tabular}

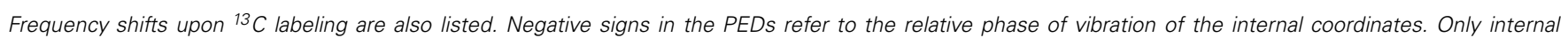
coordinates that contribute at least $5 \%$ are shown. Mode frequencies were scaled by 0.9718 .

spectra obtained using PBRCs that have had several different quinones incorporated into the $\mathrm{Q}_{\mathrm{A}}$ binding site. The fact that the many different spectra can all be modeled is a clear indicator of the appropriateness of the approach.

The calculated spectra appear not to depend on whether the quinone incorporated has a prenyl/phytyl unit or a methyl group attached at $\mathrm{C}_{6}$. The electronic structure of the quinone ring is therefore, not sensitive to the presence or absence of a hydrocarbon side chain at $\mathrm{C}_{6}$. This suggests that the hydrocarbon side chain does not significantly constrain the quinone ring in the $\mathrm{Q}_{\mathrm{A}}$ binding site.

Comparison of the calculated and experimental spectra, in combination with a consideration of the calculated PEDs of the

\section{REFERENCES}

Bandaranayake, K., Sivakumar, V., Wang, R., and Hastings, G. (2006). Modeling the $A_{1}$ binding site in photosystem I. Density functional theory for the calculation of "Anion - Neutral" FTIR difference spectra of phylloquinone. Vib. Spectrosc. 42, 78-87. doi: 10.1016/j. vibspec.2006.01.003

Breton, J. (1997). Efficient exchange of the primary quinone acceptor $\mathrm{Q}_{\mathrm{A}}$ in isolated reaction centers of Rhodopseudomonas viridis. Proc. Natl. Acad. Sci. U.S.A. 94, 11318-11323. doi: 10.1073/pnas.94. 21.11318

Breton, J., Burie J. R., Boullais, C., Berger, G., and Nabedryk, E. (1994a). Binding sites of quinones in photosynthetic bacterial reaction centers investigated by light-induced FTIR difference spectroscopy: binding of chainless symmetrical quinones to the $\mathrm{Q}_{\mathrm{A}}$ site of Rhodobacter sphaeroides. Biochemistry 33, 12405-12415. doi: 10.1021/bi00207a007

Breton, J., Burie, J. R., Berthomieu, C., Berger, G., and Nabedryk, E. (1994b). The binding sites of quinones in photosynthetic bacterial reaction centers investigated by light-induced FTIR difference spectroscopy: assignment of the $\mathrm{Q}_{\mathrm{A}}$ vibrations in Rhodobacter sphaeroides using ${ }^{18} \mathrm{O}$ - or ${ }^{13} \mathrm{C}$ labeled ubiquinone and vitamin $\mathrm{K}_{1}$. Biochemistry 33, 4953-4965. doi: 10.1021/bi00182a026

Breton, J., Boullais, C., Burie, J. R., Nabedryk, E., and Mioskowski, C. (1994c). Binding sites of quinones in photosynthetic bacterial reaction centers investigated by light-induced FTIR difference spectroscopy: assignment of the interactions of each carbonyl of $\mathrm{Q}_{\mathrm{A}}$ in Rhodobacter sphaeroides using site-specific ${ }^{13} \mathrm{C}$-labeled ubiquinone. Biochemistry 33, 14378-14386. doi: 10.1021/bi0025 $2 \mathrm{a} 002$

Breton, J., and Nabedryk, E. (1996). Protein-quinone interactions in the bacterial photosynthetic reaction center: light-induced FTIR difference spectroscopy of the quinone vibrations. Biochim. Biophys. Acta. 1275, 84-90. doi: 10.1016/00052728(96)00054-0

Brudler, R., de Groot, H. J., van Liemt, W. B., Steggerda, W. F., Esmeijer, R., Gast, P., et al. (1994). Asymmetric binding of the 1and $4-\mathrm{C}=\mathrm{O}$ groups of $\mathrm{QA}$ in Rhodobacter sphaeroides R26 reaction centres monitored by Fourier

normal modes, allows a direct assessment of the appropriateness of previous suggestions as to the origin of the bands in the experimental spectra.

\section{ACKNOWLEDGMENTS}

This work was supported in part by a grant from the Qatar National Research Fund to Gary Hastings (grant \# NPRP 4-1831-034). Nan Zhao acknowledges support from a fellowship from the Molecular Basis of Disease program at GSU. Calculations were undertaken using the IBM System p7 supercomputer (called CARINA) at GSU. This computer was acquired through a partnership of the Southeastern Universities Research Association and IBM, with additional support from the Georgia Research Alliance.

transform infra-red spectroscopy using site-specific isotopically labelled ubiquinone-10. EMBO J. 13, 5523-5530.

Case, D. A., Cheatham, T. E., Darden, T., Gohlke, H., Luo, R., Merz, K. M., et al. (2005). The Amber biomolecular simulation programs. J. Comput. Chem. 26, 1668-1688. doi: $10.1002 /$ jcc. 20290

Frisch, M. J., Trucks, G. W., Schlegel, H. B., Scuseria, G. E., Robb, M. A., Cheeseman, J. R., et al. (2004). Gaussian 03, Revision C.02. Gaussian 03, Revision D.01.

Hale, M. B., Blankenship, R. E., and Fuller, R. C. (1983). Menaquinone is the sole quinone in the facultatively aerobic green photosynthetic bacterium Chloroflexus aurantiacus. Biochim. Biophys. Acta 723 376-382. doi: 10.1016/0005-2728 (83)90044-0

Hucke, O., Schmid, R., and Labahn, A. (2002). Exploring the primary electron acceptor (QA)-site of the bacterial reaction center from Rhodobacter sphaeroides. Binding mode of vitamin $\mathrm{K}$ derivatives. Eur. J. Biochem. 269, 1096-1108. doi: 10.1046/j.0014-2956.2001.02699.x

Ke, B. (2001a). "The bacterial photosynthetic reaction center: chemical composition and crystal structure," in Photosynthesis: Photobiochemistry and Photobiophysics, (Dordrecht; Boston: Kluwer Academic Publishers), 47-62.

$\mathrm{Ke}$, B. (2001b). "The stable primary acceptor QA and the secondary electron acceptor QB," in Photosynthesis: Photobiochemistry and Photobiophysics, (Dordrecht; Boston: Kluwer Academic Publishers), 289-304.

Ke, B. (2001c). "The "Stable" primary electron acceptor (QA) of photosynthetic bacteria," in Photosynthesis: Photobiochemistry and Photobiophysics, (Dordrecht; Boston: Kluwer Academic Publishers), 101-110.

Ke, B. B. (2001d). "The secondary electron acceptor (QB) of photosynthetic bacteria," in Photobiochemistry and Photobiophysics, (Dordrecht; Boston: Kluwer Academic Publishers), 111-128.

Lamichhane, H. P., and Hastings, G. (2011). Calculated vibrational properties of pigments in protein binding sites. Proc. Natl. Acad. Sci. U.S.A. 108, 10526-10531. doi: 10.1073/pnas. 1104046108

Lamichhane, H. P., and Hastings, G. (2013). Calculated vibrational properties of ubisemiquinones. Comput. 
Biol. J. 2013:11. doi: 10.1155/2013/ 807592

Lamichhane, H., Wang, R., and Hastings, G. (2010). Comparison of calculated and experimental FTIR spectra of specifically labeled ubiquinones. Vib. Spectrosc. 55, 279-286. doi: 10.1016/j.vibspec. 2010.12.008

Lamichhane, H., Wang, R. L., and Hastings, G. (2011). Comparison of calculated and experimental FTIR spectra of specifically labeled ubiquinones. Vib. Spectrosc. 55, 279-286. doi: 10.1016/j.vibspec. 2010.12.008

Lin, T., and O'Malley, P. (2008). An ONIOM study of the $\mathrm{Q}(\mathrm{A})$ site semiquinone in the Rhodobacter sphaeroides photosynthetic reaction centre. J. Mol. Struct. Theochem. 870, 31-35. doi: 10.1016/ j.theochem.2008.08.034

Martin, J. M. L., and Van Alsenoy, C. (1995). GAR2PED. Antwerp: University of Antwerp.

McComb, J. C., Stein, R. R., and Wraight, C. A. (1990). Investigations on the influence of headgroup substitution and isoprene side-chain length in the function of primary and secondary quinones of bacterial reaction centers. Biochim. Biophys. Acta 1015, 156-171. doi: 10.1016/0005-2728(90)90227-U

Noguchi, T., and Berthomieu, C. (2005). "Molecular analysis by vibrational spectroscopy," in Photosystem II The Light Driven Water:Plastoquinone Oxidoreductase, eds T. Wydrzynski and K. Satoh (Dordrecht: Springer), 367-387.

Parameswaran, S., Wang, R., and Hastings, G. (2008). Calculation of the vibrational properties of chlorophyll a in solution. J. Phys. Chem. B 112, 14056-14062. doi: $10.1021 / j p 806115 q$

Shopes, R. J., and Wraight, C. A. (1985). The acceptor quinone complex of Rhodopseudomonas viridis reaction centers. Biochim. Biophys. Acta 806, 348-356. doi: 10.1016/00052728(85)90242-7

Sinnecker, S., Flores, M., and Lubitz, W. (2006). Protein-cofactor interactions in bacterial reaction centers from Rhodobacter sphaeroides R26: effect of hydrogen bonding on the electronic and geometric structure of the primary quinone. A density functional theory study. Phys. Chem. Chem. Phys. 8, 5659-5670. doi: $10.1039 / \mathrm{b} 612568 \mathrm{a}$

Srinivasan, N., and Golbeck, J. H. (2009). Protein-cofactor interactions in bioenergetic complexes: the role of the A1A and A1B phylloquinones in Photosystem I. Biochim. Biophys. Acta 1787, 1057-1088. doi: 10.1016/j.bbabio.2009.04.010

Stowell, M. H., McPhillips, T. M., Rees, D. C., Soltis, S. M., Abresch, E., and Feher, G. (1997). Light-induced structural changes in photosynthetic reaction center: implications for mechanism of electronproton transfer. Science 276, 812-816. doi: 10.1126/science.276. 5313.812

Trumpower, B. (1982). Function of Quinones in Energy Conserving Systems. New York, NY: Academic Press.

Vreven, T., Byun, K. S., Komaromi, I., Dapprich, S., Montgomery, J. A., Morokuma, K., et al. (2006). Combining quantum mechanics methods with molecular mechanics methods in ONIOM. J. Chem. Theory Comput. 2, 815-826. doi: $10.1021 / \mathrm{ct} 050289 \mathrm{~g}$

Warncke, K., Gunner, M. R., Braun, B. S., Gu, L. Q., Yu, C. A., Bruce, J. M., et al. (1994). Influence of hydrocarbon tail structure on quinone binding and electrontransfer performance at the $\mathrm{Q}(\mathrm{a})$ and $\mathrm{Q}(\mathrm{B})$ sites of the photosynthetic reaction-center protein. Biochemistry 33, 7830-7841. doi: 10.1021/bi00191a010

Wheeler, R. A. (2001). "Quinones and quinoidal radicals in photosynthesis," in Theoretical Biochemistry-Processes and Properties of Biological Systems, ed L. A. Eriksson (Amsterdam: Elsevier), 655-690. doi: 10.1016/ S1380-7323(01)80016-9

Wraight, C. A., and Gunner, M. R. (2009). "The acceptor quinones of purple photosynthetic bacteriastructure and spectroscopy," in The Purple Photosynthetic Bacteria, eds
C. Hunter, F. Daldal, M. Thurnauer, and T. Beatty (Dordrecht: Springer), 379-405.

Conflict of Interest Statement: The authors declare that the research was conducted in the absence of any commercial or financial relationships that could be construed as a potential conflict of interest.

Received: 29 June 2013; paper pending published: 17 July 2013; accepted: 02 August 2013; published online: 30 August 2013.

Citation: Zhao N, Lamichhane HP and Hastings $G$ (2013) Comparison of calculated and experimental isotope edited FTIR difference spectra for purple bacterial photosynthetic reaction centers with different quinones incorporated into the $Q_{A}$ binding site. Front. Plant Sci. 4:328. doi: $10.3389 / \mathrm{fpls}$.2013.00328

This article was submitted to Plant Physiology, a section of the journal Frontiers in Plant Science.

Copyright (C) 2013 Zhao, Lamichhane and Hastings. This is an open-access article distributed under the terms of the Creative Commons Attribution License (CC BY). The use, distribution or reproduction in other forums is permitted, provided the original author(s) or licensor are credited and that the original publication in this journal is cited, in accordance with accepted academic practice. No use, distribution or reproduction is permitted which does not comply with these terms. 